Cronfa - Swansea University Open Access Repository

This is an author produced version of a paper published in :

Climate Dynamics

Cronfa URL for this paper:

http://cronfa.swan.ac.uk/Record/cronfa23984

\title{
Paper:
}

Hafner, P., McCarroll, D., Robertson, I., Loader, N., Gagen, M., Young, G., Bale, R., Sonninen, E. \& Levani, T. (2014). A 520 year record of summer sunshine for the eastern European Alps based on stable carbon isotopes in larch tree rings. Climate Dynamics, 43(3-4), 971-980.

http://dx.doi.org/10.1007/s00382-013-1864-z

This article is brought to you by Swansea University. Any person downloading material is agreeing to abide by the terms of the repository licence. Authors are personally responsible for adhering to publisher restrictions or conditions. When uploading content they are required to comply with their publisher agreement and the SHERPA RoMEO database to judge whether or not it is copyright safe to add this version of the paper to this repository. http://www.swansea.ac.uk/iss/researchsupport/cronfa-support/ 


\section{A 520 year record of summer sunshine for the eastern European Alps based on stable carbon isotopes in larch tree rings.}

Polona Hafner, Danny McCarroll, Iain Robertson, Neil J. Loader, Mary Gagen, Giles HF Young, Roderick J. Bale, Eloni Sonninen, Tom Levanič

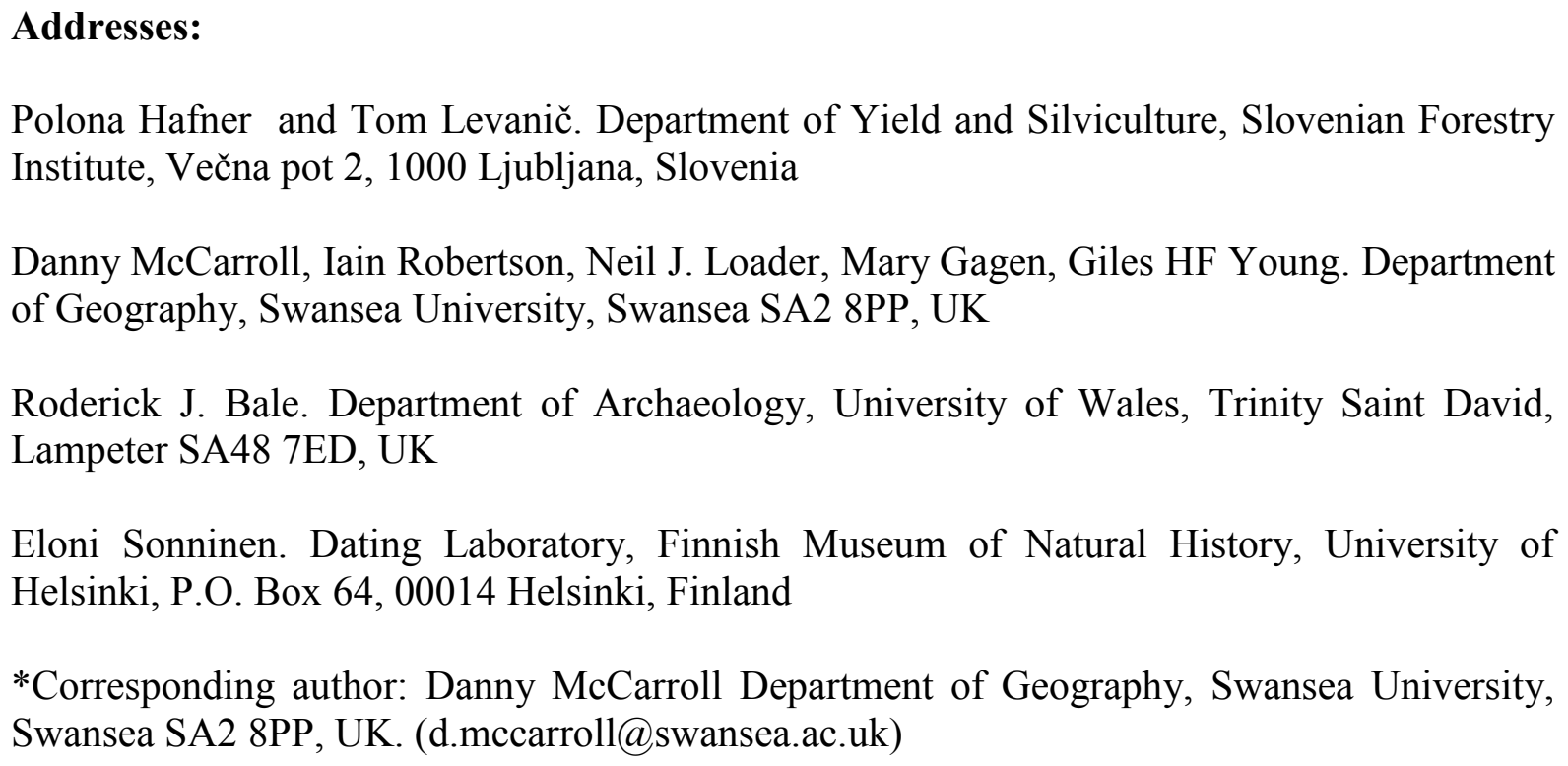

Eloni Sonninen. Dating Laboratory, Finnish Museum of Natural History, University of Helsinki, P.O. Box 64, 00014 Helsinki, Finland

*Corresponding author: Danny McCarroll Department of Geography, Swansea University, Swansea SA2 8PP, UK. (d.mccarroll@swansea.ac.uk)

\section{Key points}

- The first summer sunshine reconstruction for the European Alps 


\section{Abstract}

A 520-year stable carbon isotope chronology from tree ring cellulose in high altitude larch trees (Larix decidua Mill.), from the eastern European Alps, correlates more strongly with summer temperature than with summer sunshine hours. However, when instrumental records of temperature and sunshine diverge after AD 1980, the tree ring time series does not follow warming summer temperatures but more closely tracks summer sunshine trends. When the tree ring stable carbon isotope record is used to reconstruct summer temperature the reconstruction is not robust. Reconstructed temperatures prior to the $20^{\text {th }}$ century are higher than regional instrumental records, and the evolution of temperature conflicts with other regional temperature reconstructions. It is concluded that sunshine is the dominant control on carbon isotope fractionation in these trees, via the influence of photosynthetic rate on the internal partial pressure of $\mathrm{CO}_{2}$, and that high summer (July-August) sunshine hours is a suitable target for climate reconstruction. We thus present the first reconstruction of summer sunshine for the eastern Alps and compare it with the regional temperature evolution.

\section{$47 \quad$ Key words}

48 Carbon isotopes; dendrochronology; climate change; cloud cover 


\section{Introduction}

51 The ring widths of larch (Larix decidua Mill) trees growing high in the eastern European

52 Alps tend to be sensitive to the temperature of June, and to a lesser extent July (Hafner et al. 2011). Stable carbon isotope ratios measured on cellulose from the same tree rings correlate with the temperature of July and August. In a pilot study Hafner et al. (2011) suggested that combining these two proxies might provide a strong record of past changes in temperature for the entire summer season, June to August. However, recent work in northern Fennoscandia has raised concerns about using stable carbon isotopes in tree rings to reconstruct temperature, even when correlation and verification with local temperature data is very strong (Young et al. 2010; Gagen et al. 2011).

The ratio of ${ }^{13} \mathrm{C}$ to ${ }^{12} \mathrm{C}$ in wood cellulose, expressed relative to a standard using the delta notation $\left(\delta^{13} \mathrm{C}\right)$, is strongly linked to the concentration of carbon dioxide inside the (leaves or) needles averaged over the growing season (McCarroll and Loader 2004). Air (containing carbon dioxide) enters the needles via the stomata and the carbon dioxide is enzymatically fixed during photosynthesis to produce carbohydrates, which are used to supply all of the needs of the growing tree, including the formation of wood cells. The main controls on the carbon isotope ratio of the resulting photosynthates are the relative rates at which $\mathrm{CO}_{2}$ enters (stomatal conductance) and is removed (photosynthetic rate) from the internal leaf spaces. In dry environments stomatal conductance dominates the $\delta^{13} \mathrm{C}$ signal, recording changes in air humidity and soil moisture availability, linked to antecedent precipitation. In cool, high altitude or high latitude settings, where moisture stress is less common, the dominant signal in $\delta^{13} \mathrm{C}$ is likely to be the rate of photosynthesis. Photosynthetic rate is linked to temperature, via the rate of production of the photosynthetic enzyme, but more commonly the limiting factor is the supply of energy in the form of photon flux, or sunlight (Beerling 1994) which 
experience frequent moisture stress is theoretically controlled more strongly by sunlight than by temperature.

Although sunlight is, in theory, the strongest control on carbon isotope fractionation under cool moist conditions, in practice $\delta^{13} \mathrm{C}$, in the recent calibration period, often correlates most strongly with summer temperature. A likely explanation is that temperature and sunshine are very strongly correlated at the inter-annual scale and temperature is measured precisely and accurately, whereas long records of photosynthetically active radiation flux are rarely available, forcing reliance on less direct measures such as hours of sunshine or percentage cloud cover.

If summer sunshine and summer temperature remained strongly and uniformly covarying over long timescales it would not matter which one was used for calibration and reconstruction, and this was the assumption in some earlier work (McCarroll and Pawellek 2001; McCarroll et al. 2003). In northern Finland, for example, $\delta^{13} \mathrm{C}$ of pine trees correlated more strongly with summer temperature than either tree ring widths or densities and also gave better verification statistics using local meteorological data (McCarroll et al. 2011). However, when this proxy was used to reconstruct summer temperature back to AD1640 (Gagen et al. 2007) it was clear that temperature estimates prior to the calibration period were too high. The offset was demonstrated by comparison with the long early instrumental temperature records from Tornedalen (Gagen et al. 2011). Similar results were obtained in north-west Norway, but in this case there was a period in the instrumental measurements where there was a clear divergence between summer temperature and percentage cloud cover, indicating that temperature and sunshine may not remain tightly coupled at non-interannual timescales (Young et al. 2010). In this case when temperature and cloud cover diverged, the $\delta^{13} \mathrm{C}$ values followed the cloud cover (sunshine) rather than temperature (Young et al. 2010). The long $\delta^{13} \mathrm{C}$ records from pine trees in northern Fennoscandia have now been robustly 
reinterpreted as records of past summer sunshine or cloud cover, depending on the availability of local meteorological data for calibration and verification (Gagen et al. 2011; Young et al. 2012; Loader et al. 2013). In this area there are very clear offsets between the tree ring $\delta^{13} \mathrm{C}$ records and high quality reconstructions of summer temperature (Melvin et al. 2012; McCarroll et al. 2013), pointing to long periods of divergence between temperature and sunshine, perhaps indicating large scale changes in circulation in the past (Loader et al. 2013). Similar divergence between summer temperature and sunshine, at decadal or multidecadal timescales, has also been found within a General Circulation Model (Gagen et al. 2011).

In the European Alps, as elsewhere, tree ring $\delta^{13} \mathrm{C}$ has generally been interpreted either as an indicator of moisture stress, in drier areas, or of summer temperature in higher, cooler ones. For example, Kress et al. (2010) measured carbon isotope ratios in larch trees from the Lötschental in the Valais; one of driest regions in Switzerland, and found very strong correlations with a drought index based on temperature and precipitation amount. In the same valley Treydte et al. (2001) reported strong correlations between $\delta^{13} \mathrm{C}$ in spruce tree rings and temperature, precipitation and relative humidity, concluding that relative humidity is a suitable target for reconstruction. In the French Alps, Daux et al. (2011) also report strong correlations between larch $\delta^{13} \mathrm{C}$ and summer relative humidity. Strong correlations with parameters linked to moisture stress have also been reported for beech trees (Saurer et al. 1997) and for pines growing at dry Alpine sites (Gagen et al. 2004, 2006). On the more moist southern side of the Swiss Alps, Reynolds-Henne et al. (2007) report a low but consistent correlation between $\delta^{13} \mathrm{C}$ in Scots pine trees and summer temperature. Alpine tree ring $\delta^{13} \mathrm{C}$ chronologies have not, thus far, been interpreted in terms of past variations in sunshine.

The aim of this paper is to use a 520 year $\delta^{13} \mathrm{C}$ chronology from the eastern Alps to test the hypothesis that, based on first principles, the dominant control on isotopic fractionation is 
summer sunshine rather than temperature in this region. Given the paucity of sunshine records over this region, this is tested by critically assessing the veracity of temperature reconstructions by comparing them with both long instrumental series and temperature reconstructions, based on other lines of evidence.

\section{Sites and data description}

Tree ring samples for isotopic analysis were obtained by sub-sampling 12 trees from a Larix decidua tree ring chronology built using living trees from two alpine (1700 m a.s.1.) sites; Dleskovška plateau $\left(46^{\circ} 21^{\prime} \mathrm{N}, 14^{\circ} 42^{\prime} \mathrm{E}\right.$, close to the border with Austria) and Vršič $\left(46^{\circ} 26^{\prime} \mathrm{N}\right.$, $13^{\circ} 43^{\prime} \mathrm{E}$, close to the border with Italy) in the Slovenian Alps (see Hafner et al. 2011 for more details of site selection). The chronology also includes some roof timbers from St. George's church in the coastal region of Slovenia (Piran, $45^{\circ} 31^{\prime} \mathrm{N}, 13^{\circ} 34^{\prime} \mathrm{E}$ ) and two of these were included to extend and strengthen the early part of the isotope chronology. The building timbers originate from 'alpine sites near the border between Slovenia and Italy' (Levanič et al. 1997).

From each tree or beam, 12-mm cores were extracted, air-dried, absolutely dated and then divided into annual tree rings using a scalpel under magnification. The youngest 50 tree rings of each tree were excluded from further analysis to avoid potential "juvenile trends" in the $\delta^{13} \mathrm{C}$ chronology (Gagen et al. 2007), although recent work on larch suggests that this might not be necessary (Daux et al. 2011). Tree rings were not separated into early and late-wood components because the rings were often too narrow to provide enough $\alpha$-cellulose and because it has been shown that for conifers the isotopic ratios of early and late wood are strongly correlated and good results are obtained when using the whole ring (Kress et al. 2009). For each tree ring the $\alpha$-cellulose was isolated using standard techniques (Loader et al. 1997; Rinne et al. 2005). The purified samples were homogenized using a Hielscher 
ultrasonic probe (Laumer et al. 2009) and freeze-dried for at least 48 hours prior to measurement of $\delta^{13} \mathrm{C}$ ratios.

152

153 Carbon isotope analysis, using samples of $0.30-0.35 \mathrm{mg}$ of $\alpha$-cellulose, was performed using 154 a mixture of combustion and pyrolysis techniques. Pyrolysis allows both carbon and oxygen isotope ratios to be measured on the same sample (Young et al. 2011a; Woodley et al. 2012), which is advantageous when dealing with thin rings, as in this study. For combustion the samples were weighed into tin capsules and combusted over chromium(III) oxide and copper(II) oxide at $1,000^{\circ} \mathrm{C}$. For pyrolysis, samples were weighed into silver capsules and pyrolysed over glassy carbon at $1,090^{\circ} \mathrm{C}$. In both cases work was conducted in the Swansea University stable isotope laboratory using a PDZ Europa ANCA GSL elemental analyzer interfaced to a PDZ Europa 20-20 stable isotope ratio mass spectrometer using the methods described by Young et al. (2011a). For comparison, samples from one tree were pyrolysed at higher temperature $\left(1,330^{\circ} \mathrm{C}\right)$ in a Finnigan TC/EA high temperature elemental analyzer interfaced (by ConFloIII) to a ThermoFinnigan DeltaPlus Advantage isotope ratio mass spectrometer at the University of Helsinki. Analytical precision was typically \pm 0.1 per mille $\left(\delta^{13} \mathrm{C}\right)$. The $\delta^{13} \mathrm{C}$ values obtained by pyrolysis and combustion on the same samples were very similar (mean values $-22.98 \%$ or for combustion and $-23.11 \%$ or for pyrolysis, correlation $\mathrm{r}=$ et al. (2011a).

172 After scaling, the $\delta^{13} \mathrm{C}$ values were corrected first to remove the atmospheric decline in the $\delta^{13} \mathrm{C}$ values of atmospheric carbon dioxide, by simple addition using an extrapolation of the values provided by McCarroll and Loader (2004), and then for changes in the response to the 
rising carbon dioxide content of the atmosphere using the pre-industrial (PIN) correction proposed by McCarroll et al. (2009). The effect of the two corrections is shown in Hafner et al. (2011). The PIN correction is based on the physiological constraints on a plastic response to rising carbon dioxide levels and makes no attempt to fit the isotope data to any climatic signal, thus preserving the independence of the meteorological data sets to be used for calibration. The effect of the PIN correction on the reconstruction was checked by including and excluding the period that is affected (discussed later).

Examination of the individual tree $\delta^{13} \mathrm{C}$ series suggests that the temporal evolution of the mean isotope curve is not an artifact of changes in sample depth or the mixture of different tree cohorts, and the longer tree series follow the trend of the mean. With only 14 trees, including cohorts of similar age, it is difficult to test conclusively for the presence of age trends. Much larger data sets for Scots pine in Fennoscandia show no evidence for an age trend after a short (<50yrs) juvenile period (Gagen et al. 2008; Young et al. 2011b) and a similar study would be required for Alpine larch, but there are insufficient published data at present. However, the trend of a linear correlation between $\delta^{13} \mathrm{C}$ and ring number provides some indication of the extent of age related trends in these trees, and seven of the trees show a rise over their series length, of which four are statistically significant $(\mathrm{p}<0.05)$, whilst the other seven show a decline, of which three are significant. There is certainly no evidence to suggest a consistent age trend in larch $\delta^{13} \mathrm{C}$ that might confound any climatic interpretation of the mean series.

Of the five calendar centuries covered by the mean $\delta^{13} \mathrm{C}$ record (Fig. 1), the highest centurymean occurs in the $18^{\text {th }}(-22.64 \%)$ followed by the $17^{\text {th }}(-22.78 \%)$ and the lowest in the $19^{\text {th }}$ $(-22.92 \%)$. Mean values of the $16^{\text {th }}$ and $20^{\text {th }}$ centuries are almost the same $(-22.88 \%$ and - 
$22.89 \%$ ). Taking half centuries, the mean value for the period 1951 to $2000(-22.79 \%$ o) is the fourth highest, with higher values covering the period AD 1651 to 1750 . The lowest is the first half of the $20^{\text {th }}$ century, followed by the first half of the $17^{\text {th }}$ century.

\section{Calibration and verification of the climate signal}

A pilot study (Hafner et al. 2011) calibrated carbon isotopes from this chronology, together with other potential paleoclimate proxies for the last 100 years, using meteorological data from Villacher Alps meteorological station in the Austrian Alps, which is part of the HISTALP network (Auer 2007). Strong positive correlations were reported with the mean temperatures of July and August, weaker but significant correlations with September temperatures but not with June. Sunshine hours in July and August also gave strong correlations, with insignificant values for June and September. Significant negative correlations were reported for the precipitation totals of July and August. The data presented here give very similar results, but we are able to extend the correlations back to AD1884, which is the length of the sunshine data (Table 1). In all cases combining the meteorological data from July and August improves the correlation with $\delta^{13} \mathrm{C}$.

Over the period for which both temperature and sunshine data are available (AD1884 to 2006), $\delta^{13} \mathrm{C}$ correlates more strongly with July to August (JA) temperature than with JA sunshine, and these two climatic variables are strongly correlated with each other $(r=0.73$, $p<0.001)$. Since JA temperature gives the highest correlation, in the absence of other information that would be the logical choice as a target for reconstruction. However, some care is required when comparing sunshine and temperature correlations, because temperature is measured with greater accuracy and precision than sunshine hours and also because 
temperature changes smoothly across space, whereas sunshine (cloudiness), and precipitation variations are more spatially variable. This means that the inter-annual temperature variations experienced in the sampled forest and measured at a distant meteorological station are likely to be more similar than the same values for sunshine, so if the real influence of temperature and sunshine on a proxy are equally strong, temperature will likely give higher correlation values due to the superior instrumental robustness and spatial homogeneity of the temperature variable.

Split-period verification tests conducted over the common period for which local temperature and sunshine data are available show that temperature may not be the best target for reconstruction (Fig. 2). The squared correlation $\left(\mathrm{R}^{2}\right)$ values over the two halves of the instrumental data are very similar for sunshine, but for temperature the correlation over the recent period (AD1946 to 2006) is much lower than that over the earlier half (AD1884 to 1945). Also, although the Reduction of Error (RE) values for temperature are higher than those for sunshine, this is not true for the more challenging Coefficient of Efficiency (CE) statistic. Low CE results indicate an offset in the absolute values of the measured and predicted temperatures. In this case the offset occurs because the temperature and sunshine records diverge after 1983and the isotope values follow the evolution of the sunshine record, rather than rising with summer temperatures.

There are two reasonable explanations for the offset between summer temperature and stable carbon isotope ratios over the last few decades. One possibility is that the offset reflects the direct influence of increasing carbon dioxide concentrations on fractionation of carbon by these trees. A correction has already been made for this effect, but the PIN correction used (McCarroll et al. 2009) only removes any decline in the isotope values that could be 
accounted for by rising $\mathrm{CO}_{2}$. Treydte et al. (2009) have proposed an alternative correction that effectively tunes the stable isotope values to the target climate variable. Applying this procedure would certainly remove the offset but the calibration and verification would be

253

254 compromised because the isotope and temperature data would no longer be independent. The alternative explanation is that the dominant control on photosynthetic rate, and therefore on stable carbon isotope fractionation, is photon flux rather than temperature and the divergence between $\delta^{13} \mathrm{C}$ and summer temperature represents the divergence between temperature and sunshine. If the strong correlation between temperature and $\delta^{13} \mathrm{C}$ is indirect, via photon flux, and recent warming is due to increased greenhouse gas concentrations, then a divergence between temperature and sunshine, and between temperature and $\delta^{13} \mathrm{C}$, is precisely what would be expected.

Given the available sunshine data, it is not possible to conclude definitively, using correlation analysis, whether the dominant signal in the $\delta^{13} \mathrm{C}$ of these larch trees is summer temperature or summer sunshine. Apart from the last few decades, where steeply rising atmospheric $\mathrm{CO}_{2}$ is a confounding factor, there are no prolonged periods of divergence between temperature and sunshine at Villacher Alps.

The veracity of a JA temperature reconstruction based on the correlation with $\delta^{13} \mathrm{C}$ can be investigated to some extent using longer gridded temperature data (Böhm et al. 2010) that is available for the Eastern Alps $\left(43^{\circ}-49^{\circ} \mathrm{N}\right.$ and $\left.12^{\circ}-19^{\circ} \mathrm{E}\right)$. Over the common period AD1851 to 2006 the Villacher Alps and eastern Alpine temperatures are very strongly correlated $(r=0.93 \mathrm{p}<0.001)$ and over that period they each give the same correlation with the $\delta^{13} \mathrm{C}$ results $(\mathrm{r}=0.56 \mathrm{p}<0.001)$. However, the eastern Alpine series extends back to AD1763, allowing much longer periods for calibration and verification. 
276 Using longer calibration and verification periods (122 years each) should reduce the impact

277 of the recent short period of clear offset, but even so, when $\delta^{13} \mathrm{C}$ values calibrated over the 278 recent period, AD1885 to 2006, are used to predict the temperatures for the earlier period, 279 AD1763 to 1884 , there is a clear overestimate of summer temperatures, resulting in a CE 280 value close to zero (Fig. 3). If the period of offset after $\mathrm{AD} 1983$ is removed, and the $\delta^{13} \mathrm{C}$ values are calibrated over AD1885 to 1983, the offset remains and in this case the verification statistics are even worse, because there is then no difference between the average temperatures over the calibration and verification periods, so that $\mathrm{RE}$ and $\mathrm{CE}$ become equivalent.

Although comparison with the long eastern Alps summer temperature record produces verification statistics that are above zero, it indicates a clear problem with interpreting $\delta^{13} \mathrm{C}$ as a record of temperature. Even if the last few decades, when rapidly rising $\mathrm{CO}_{2}$ causes some uncertainty in the $\delta^{13} \mathrm{C}$ values, are ignored, it is clear that $\delta^{13} \mathrm{C}$ will tend to overestimate the temperature of the past. The reason is simply that although the mean JA temperature for the period $\mathrm{AD} 1760$ to 1884 is the same as that for $\mathrm{AD} 1885$ to 1983 , the mean $\delta^{13} \mathrm{C}$ values for the earlier period are higher than those for the recent period. Unfortunately, meteorological records are not sufficiently long to determine whether there is a similar long-term offset between temperature and sunshine or cloud cover.

296 Comparisons of the $\delta^{13} \mathrm{C}$ chronology with other reconstructions of summer temperature for 297 the Alpine region also suggest that temperature is not the appropriate interpretation (Fig. 4). Documentary evidence provides perhaps the most powerful proxy measure of past temperature (Brázdil et al. 2005, 2010) and reconstructions with monthly resolution, based 
mainly on data from Switzerland, Germany and the Czech lands, have been provided by Dobrovolný et al. (2010). When the $\delta^{13} \mathrm{C}$ chronology is scaled to the mean documentarybased JA temperature values there are many clear anomalies and long periods where the two records disagree, despite being forced to the same mean value over the common period AD1500 to AD1854. The isotopes underestimate temperatures between AD1630 and 1660, but generally overestimate between AD1660 and 1840. Very high over-estimates occur in $\mathrm{AD} 1600$ and $1601\left(3.75\right.$ and $\left.3.95^{\circ} \mathrm{C}\right)$ and between $\mathrm{AD} 1692$ and 1697 (3.24 ${ }^{\circ} \mathrm{C}$ in 1694$) . \mathrm{A}$ similar comparison with the longer reconstruction of JJA temperature by Trachsel et al. (2012), although scaled over a different period (AD1486 to 1996) shows a similar pattern of prolonged offsets. In particular, whereas the Trachsel et al. (2012) record shows a long-term increase between about AD 1700 and 1950, the isotope record shows a long-term decline. The period between AD1825 and 1996 is almost continuously negative.

An alternative and arguably more reasonable interpretation of the long-term evolution of the $\delta^{13} \mathrm{C}$ chronology is that it represents mainly changes in sunshine. If this is true then comparing the $\delta^{13} \mathrm{C}$ curve with temperature reconstructions may reveal periods when sunshine and temperature were less coupled than they appear to be over the period for which sunshine records are available. Using both the documentary (Dobrovolný et al. 2010) and multi-proxy based reconstructions (Trachsel et al. 2012) there are several clear periods where temperature and $\delta^{13} \mathrm{C}$ (interpreted for sunshine) behave in-phase, but several where they diverge (Fig. 4, Fig 5). The period between about AD1570 and 1590 stands out as particularly cold and cloudy, whereas the years around AD1600 were sunny. Between AD1625 and 1650 it was not cold but very cloudy and as temperatures declined in the second half of the $17^{\text {th }}$ century it become increasingly sunny, culminating in the sunniest period in the record in the first decade of the $18^{\text {th }}$ century, when it was also warm. Most of the remainder of the $18^{\text {th }}$ 
century is unremarkable, with both temperature and sunshine oscillating close to the values experienced in the latter half of the $20^{\text {th }}$ century, apart from the AD1790s, which were sunny. From AD1800 to 1825 it is both cold and cloudy. Between AD1825 and 1875 there is a rise in temperature but a drop in sunshine, so that compared to the last half millennium, the period between $\mathrm{AD} 1825$ and 1940 is relatively warm but cloudy. It is notable that when the $\delta^{13} \mathrm{C}$ record is scaled over a very long period, to match the Trachsel et al. (2012) reconstruction, and expressed in anomalies relative to the $20^{\text {th }}$ century, the offset between temperature and sunshine of the last few decades does not look unusual at all.

\section{Sunshine reconstruction based on $\delta^{13} \mathrm{C}$}

Given the long term evolution of the $\delta^{13} \mathrm{C}$ chronology, and the reasonably good correlation with measured values, we propose that July/August sunshine is the most appropriate target for climate reconstruction using stable carbon isotope ratios in larch trees growing at high elevation in the southeastern Alps. Climate reconstructions based on regression (inverse calibration; using the proxy to predict climate) always underestimate the variability of climate in the past, the magnitude of the effect being proportional to the amount of unexplained variance (McCarroll et al. 2013). Given a correlation of $r=0.55$ with the total hours of sunshine for July and August combined, a regression-based reconstruction grossly underestimates the variability of sunshine over the period of measurement, so the reconstruction has been scaled to match the mean and variance of the meteorological data (Fig. 6).

It must be stressed that this sunshine reconstruction needs to be interpreted with caution. It is based upon a small sample of trees from only two sites and the uncertainty around the annual values is very large. Ignoring uncertainty in the estimate of the mean isotope values, two 
standard errors of the prediction gives \pm 102 hours of sunshine. However, it is the first such reconstruction for the Alpine region and when considered alongside reconstructions of temperature and precipitation may provide a more synoptic view of changes in climate over time.

Three years stand out as having very high isotope and predicted sunshine values: AD2006, AD1911 and AD1705. The autumn of AD2006 was exceptionally warm and dry (Luterbacher et al. 2007). The summer of AD1911 was both hot and sunny and it also had the lowest July/August rainfall in all the available records. The scaled reconstruction over-estimates sunshine and this probably represents increased stomatal control on fractionation due to very dry conditions. Similar conditions would explain the very high value for AD1705, and in the summer (July-August) temperature reconstruction of Dobrovolný (2010) AD1705 is strongly positive, and is warmer than AD1706. AD1706 in the Casty et al. (2005) reconstructions is listed as one of the warmest and driest summers, but those records also include June. Other very sunny summers include: AD1696, 1719, 1600 and 1601.

Two summers have anomalously low isotope values: AD1840 and 1913. The summer of 1913 was very wet and cold and although sunshine measured at Villacher Alps was not anomalously low, it may have been considerably cloudier at the field site. The summer of AD1840 was cold but is not listed by Casty et al. (2005) as particularly wet regionally. Other summers inferred to be very cloudy include: AD1804, 1580, 1868, 1582, 1630 and 1850.

\section{Discussion and conclusions}

Although $\delta^{13} \mathrm{C}$ from high altitude larch trees in the Slovenian Alps correlate most strongly with mid to late summer temperature, we conclude that the dominant control, and most suitable target for reconstruction is actually mid- to late-summer sunshine. This argument is based on four lines of evidence: 
1. Mechanistic models of carbon isotopic fractionation by trees suggest that the dominant control can be either stomatal conductance or photosynthetic rate. Photosynthetic rate is controlled more strongly by sunshine (photon flux) than it is by temperature.

2. Since the 1980 s there has been an increase in summer temperature but not in hours of summer sunshine. The $\delta^{13} \mathrm{C}$ results follow the stable sunshine data rather than the rising temperature record.

3. Even if the recent period of divergence between summer temperature and sunshine is ignored, when $\delta^{13} \mathrm{C}$ is calibrated over the last century it tends to overestimate the measured summer temperatures of the past. This is not the case when sunshine is the reconstruction target.

4. If $\delta^{13} \mathrm{C}$ is calibrated to temperature it produces a time-series that conflicts with other temperature reconstructions for the Alpine region that are based on strong evidence.

The summer sunshine reconstruction that we provide is the first for the Alpine region, but it needs to be treated with caution. It is calibrated using the best available data, which is total hours of sunshine of July and August, which is not the same as the mechanistic control on fractionation, which we suggest would be photosynthetically active radiation (PAR). Given a correlation between carbon isotope ratios and hours of summer sunshine of 0.55 , only about $30 \%$ of the variance in the isotope chronology is explained by the available sunshine record. We would normally avoid using isotopes for climate reconstruction unless about half of the variance is explained (McCarroll et al. 2003), but since this is a novel interpretation of this proxy in an Alpine setting it is presented to encourage discussion and critique. A more reliable reconstruction would require greater replication and sampling of trees from several 
different sites, but even then the quality of the calibration might be compromised because of the paucity of suitable meteorological data.

398

399

400

401

402

403

404

405

406

407

408

409

410

411

412

413

414

415

416

417

418

If the $\delta^{13} \mathrm{C}$ chronology is interpreted in terms of changes in sunshine rather than temperature, it likely provides a more synoptic view of changing climate over the last 500 years. Perhaps the harshest period of the Little Ice Age in the Alps, between AD1560 and 1600 is the largest negative anomaly in terms of sunshine, and this is followed by another cloudy period in the first half of the $17^{\text {th }}$ century. The second half of the $17^{\text {th }}$ century sees sunshine increase and the $18^{\text {th }}$ century is generally sunnier than the $20^{\text {th }}$. Between AD1800 and 1950 there is a general decline in sunshine followed by a recovery in the last 60 years.

There is no reason to expect sunshine records in northern Fennoscandia to correlate with those in the Alps, but there are some similarities that are worthy of note. In both areas the $18^{\text {th }}$ and $19^{\text {th }}$ centuries were generally sunnier than the $20^{\text {th }}$ century and in both areas there are cold intervals that were relatively sunny and warmer intervals that were cloudy, indicating divergence of temperature and sunshine at multi-decadal timescales. However, just as the periods of most extreme warm and cold summers do not coincide between the two regions, so the sunniest and cloudiest periods are also out of phase.

If temperature and sunshine have not remained strongly coupled at multi-decadal timescales in the Alpine region it has implications for understanding and modelling climate change. The influence of changing temperatures on clouds, and therefore on sunshine, is the greatest source of uncertainty in the modeling of climate change (Trenberth and Fasullo 2009; Gagen et al. 2011). Reliable records of the changing relationship between temperature and sunshine over a long period would provide a powerful test of the ability of general circulation models to deal effectively with temperature/cloud feedbacks. The European Alps is an area with unrivalled evidence of changes in past temperature (Dobrovolný et al. 2010; Trachsel et al. 
420 2012) but given that the sunshine reconstruction is based on a single $\delta^{13} \mathrm{C}$ chronology, it 421 would be imprudent to use the relationship between temperature and sunshine presented here

422 for model evaluation. Greater replication and addition of different field sites would 423 strengthen the record, but will not deal with the problem of calibration. Perhaps the most 424 powerful test of the hypothesis that tree ring $\delta^{13} \mathrm{C}$ chronologies can represent changes in 425 sunshine would be an independent reconstruction of a sunshine parameter based on the 426 wealth of documentary sources that have been collected for this region (Brázdil et al. 2010).

427 A reconstruction of past changes in circulation, using stable oxygen isotopes in tree rings, 428 might also help to explain periods of divergence between sunshine and temperature and also 429 account for the temporal offsets in climate extremes in different regions.

\section{Acknowledgements}

431 This work was conducted as part of the EU-funded Millennium project 017008. We 432 acknowledge Program and Research group Forest Biology, Ecology and Technology (P4433 0107), EU-Forinno, C3W and the Slovenian research agency - Young researcher program 434 (PH).We thank Dave Frank and Matthias Trachsel for helpful advice and two anonymous 435 reviewers for their very constructive criticism. 


\section{References}

440 Auer, I., et al. (2007), HISTALP - historical instrumental climatological surface time series

441 of the Greater Alpine Region, International Journal of Climatology, 27(1), 17-46.

442 Beerling, D. J. (1994), Predicting leaf gas-exchange and delta-c-13 responses to the past 44330000 years of global environmental-change, New Phytologist, 128(3), 425-433.

444 Böhm, R., Jones, P.D., Hiebl, J., Brunetti, M., Frank, D., Maugeri, M., 2010. The early 445 instrumental warm bias: a solution for long central European temperatures series 1760 446 2007. Climatic Change 101, 41-67.

447 Brázdil, R., C. Pfister, H. Wanner, H. Von Storch, and J. Luterbacher (2005), Historical 448 climatology in Europe - The state of the art, Climatic Change, 70(3), 363-430. 450 (2010), European climate of the past 500 years: new challenges for historical climatology, 451 Climatic Change, 101(1-2), 7-40. P. Zetterberg (1990), A 1,400-year tree-ring record of summer temperatures in

454 fennoscandia, Nature, 346(6283), 434-439.

455 Casty, C., H. Wanner, J. Luterbacher, J. Esper, and R. Bohm (2005), Temperature and 456 precipitation variability in the european Alps since 1500, International Journal of

457 Climatology, 25(14), 1855-1880. 
Danis PA, Guibal F (2011) Can climate variations be inferred from tree-ring parameters and stable isotopes from Larix decidua? Juvenile effects, budmoth outbreaks, and divergence issue. Earth and Planetary Science Letters 309:221-233

Dobrovolný, P., et al. (2010), Monthly, seasonal and annual temperature reconstructions for Central Europe derived from documentary evidence and instrumental records since AD 1500, Climatic Change, 101(1-2), 69-107.

Farquhar, G. D., M. H. Oleary, and J. A. Berry (1982), On the relationship between carbon isotope discrimination and the inter-cellular carbon-dioxide concentration in leaves, Australian Journal of Plant Physiology, 9(2), 121-137.

Gagen, M., D. McCarroll, and J. L. Edouard (2004), Latewood width, maximum density, and stable carbon isotope ratios of pine as climate indicators in a dry subalpine environment, French Alps, Arctic Antarctic and Alpine Research, 36(2), 166-171.

Gagen, M., D. McCarroll, and J. L. Edouard (2006), Combining ring width, density and stable carbon isotope proxies to enhance the climate signal in tree-rings: An example from the southern French Alps, Climatic Change, 78(2-4), 363-379. (2007), Exorcising the 'segment length curse': Summer temperature reconstruction since AD 4771640 using non-detrended stable carbon isotope ratios from pine trees in northern Finland, Holocene, 17(4), 435-446. 
479 Gagen, M., D. McCarroll, I. Robertson, N. J. Loader, and R. Jalkanen (2008), Do tree ring 480 delta C-13 series from Pinus sylvestris in northern Fennoscandia contain long-term non481 climatic trends?, Chemical Geology, 252(1-2), 42-51.

482 Gagen, M., E. Zorita, D. McCarroll, G. H. F. Young, H. Grudd, R. Jalkanen, N. J. Loader, I. 483 Robertson, and A. Kirchhefer (2011), Cloud response to summer temperatures in 484 Fennoscandia over the last thousand years, Geophysical Research Letters, 38.

485

486

487

488

489

490

491

492

493

494

495

496

497

498

499

500

Hafner, P., I. Robertson, D. McCarroll, N. J. Loader, M. Gagen, R. J. Bale, H. Jungner, E. Sonninen, E. Hilasvuori, and T. Levanič (2011), Climate signals in the ring widths and stable carbon, hydrogen and oxygen isotopic composition of Larix decidua growing at the forest limit in the southeastern European Alps, Trees-Structure and Function, 25(6), 11411154.

Kress, A., G. H. F. Young, M. Saurer, N. J. Loader, R. T. W. Siegwolf, and D. McCarroll (2009), Stable isotope coherence in the earlywood and latewood of tree-line conifers, Chemical Geology, 268(1-2), 52-57.

Kress, A., M. Saurer, R. T. W. Siegwolf, D. C. Frank, J. Esper, and H. Bugmann (2010), A 350 year drought reconstruction from Alpine tree ring stable isotopes, Global Biogeochemical Cycles, 24.

Laumer, W., L. Andreu, G. Helle, G. H. Schleser, T. Wieloch, and H. Wissel (2009), A novel approach for the homogenization of cellulose to use micro-amounts for stable isotope analyses, Rapid Communications in Mass Spectrometry, 23(13), 1934-1940.

Levanič, T, K. Čufar, J. Hudolin, B. Benko-Mächtig (1997), Dendrokronološka analiza strešne konstrukcije župne cerkve sv. Jurija v Piranu (občina Piran, Slovenija) = 
501

502

503

504

505

506

507

508

509

510

511

512

513

514

515

516

517

518

519

520

521

522

Dendrochronological analysis of the roof construction of the church of st. George in Piran (municipality of Piran, Slovenia). Ann, Ser. hist. sociol. 10, 43-52. [COBISS.SI-ID 168073]

Loader, N. J., I. Robertson, A. C. Barker, V. R. Switsur, and J. S. Waterhouse (1997), An improved technique for the batch processing of small wholewood samples to alphacellulose, Chemical Geology, 136(3-4), 313-317.

Loader, N. J., G. H. F. Young, H. Grudd, and D. McCarroll (2013), Stable carbon isotopes from Tornetrask, northern Sweden provide a millennial length reconstruction of summer sunshine and its relationship to Arctic circulation, Quaternary Science Reviews, 62, 97-113.

Luterbacher, J., M. A. Liniger, A. Menzel, N. Estrella, P. M. Della-Marta, C. Pfister, T. Rutishauser, and E. Xoplaki (2007), Exceptional European warmth of autumn 2006 and winter 2007: Historical context, the underlying dynamics, and its phenological impacts, Geophysical Research Letters, 34(12), 6.

McCarroll, D., and N. J. Loader (2004), Stable isotopes in tree rings, Quaternary Science Reviews, 23(7-8), 771-801.

McCarroll, D., and F. Pawellek (2001), Stable carbon isotope ratios of Pinus sylvestris from northern Finland and the potential for extracting a climate signal from long Fennoscandian chronologies, Holocene, 11(5), 517-526.

McCarroll, D., R. Jalkanen, S. Hicks, M. Tuovinen, M. Gagen, F. Pawellek, D. Eckstein, U. Schmitt, J. Autio, and O. Heikkinen (2003), Multiproxy dendroclimatology: a pilot study in northern Finland, Holocene, 13(6), 829-838.

McCarroll, D., M. H. Gagen, N. J. Loader, I. Robertson, K. J. Anchukaitis, S. Los, G. H. F. Young, R. Jalkanen, A. Kirchhefer, and J. S. Waterhouse (2009), Correction of tree ring 
stable carbon isotope chronologies for changes in the carbon dioxide content of the atmosphere, Geochimica Et Cosmochimica Acta, 73(6), 1539-1547.

McCarroll, D., M. Tuovinen, R. Campbell, M. Gagen, H. Grudd, R. Jalkanen, N. J. Loader, and I. Robertson (2011), A critical evaluation of multi-proxy dendroclimatology in northern Finland, Journal of Quaternary Science, 26(1), 7-14.

McCarroll, D., N.J Loader, R. Jalkanen, M. H. Gagen, H. Grudd, B. E. Gunnarson, A. J. Kirchhefer, M. Friedrich, H. W. Linderholm, M. Lindholm, T. Boettger, S. O. Los, S. Remmele, Y. M. Kononov, Y. H. Yamazaki, G. H. F. Young, E. Zorita (2013_. A 1200-year multi-proxy record of tree growth and summer temperature at the northern pine forest limit of Europe. The Holocene 23, 471-484. DOI: 10.1177/0959683612467483

Melvin, T., H. Grudd, K. R. Briffa (2012) Potential bias in 'updating' tree ring chronologies using regional curve standardisation: Re-processing 1500 years of Torneträsk density and ring-width data The Holocene, 23, 364-373. doi:10.1177/0959683612460791.

Reynolds-Henne, C. E., R. T. W. Siegwolf, K. S. Treydte, J. Esper, S. Henne, and M. Saurer (2007), Temporal stability of climate-isotope relationships in tree rings of oak and pine (Ticino, Switzerland), Global Biogeochemical Cycles, 21(4).

Rinne, K. T., T. Boettger, N. J. Loader, I. Robertson, V. R. Switsur, and J. S. Waterhouse (2005), On the purification of alpha-cellulose from resinous wood for stable isotope $(\mathrm{H}, \mathrm{C}$ and O) analysis, Chemical Geology, 222(1-2), 75-82.

Saurer, M., S. Borella, F. Schweingruber, and R. Siegwolf (1997), Stable carbon isotopes in tree rings of beech: Climatic versus site-related influences, Trees-Structure and Function, 11(5), 291-297. 
Trachsel, M., et al. (2012), Multi-archive summer temperature reconstruction for the European Alps, AD 1053-1996, Quaternary Science Reviews, 46, 66-79.

Trenberth, K. E., and J. T. Fasullo (2009), Global warming due to increasing absorbed solar radiation, Geophysical Research Letters, 36.

Treydte, K., G. H. Schleser, F. H. Schweingruber, and M. Winiger (2001), The climatic significance of delta C-13 in subalpine spruces (Lotschental, Swiss Alps) - A case study with respect to altitude, exposure and soil moisture, Tellus Series B-Chemical and Physical Meteorology, 53(5), 593-611.

Treydte, K. S., D. C. Frank, M. Saurer, G. Helle, G. H. Schleser, and J. Esper (2009), Impact of climate and $\mathrm{CO} 2$ on a millennium-long tree-ring carbon isotope record, Geochimica et Cosmochimica Acta, 73(16), 4635-4647.

Woodley, E. J., N. J. Loader, D. McCarroll, G. H. F. Young, I. Robertson, T. H. E. Heaton, M. H. Gagen, and J. O. Warham (2012), High-temperature pyrolysis/gas chromatography/isotope ratio mass spectrometry: simultaneous measurement of the stable isotopes of oxygen and carbon in cellulose, Rapid Communications in Mass Spectrometry, 26(2), 109-114.

Young, G. H. F., D. McCarroll, N. J. Loader, and A. J. Kirchhefer (2010), A 500-year record of summer near-ground solar radiation from tree-ring stable carbon isotopes, Holocene, 20(3), 315-324.

Young, G. H. F., N. J. Loader, and D. McCarroll (2011a), A large scale comparative study of stable carbon isotope ratios determined using on-line combustion and low-temperature pyrolysis techniques, Palaeogeography Palaeoclimatology Palaeoecology, 300(1-4), 23-28. 
567 Young, G. H. F., J. C. Demmler, B. E. Gunnarson, A. J. Kirchhefer, N. J. Loader, and D.

568 McCarroll (2011b), Age trends in tree ring growth and isotopic archives: A case study of

569 Pinus sylvestris L. from northwestern Norway, Global Biogeochemical Cycles, 25.

570 Young, G. H. F., D. McCarroll, N. J. Loader, M. H. Gagen, A. J. Kirchhefer, and J. C.

571 Demmler (2012), Changes in atmospheric circulation and the Arctic Oscillation preserved

572 within a millennial length reconstruction of summer cloud cover from northern

573 Fennoscandia, Climate Dynamics, 39(1-2), 495-507.

574 
575 Tables

576 Table 1. Pearson's correlation coefficients and statistical significance (p) of the correlation 577 between climate variables and $\delta^{13} \mathrm{C}$ over the common period AD1884-2006.

\begin{tabular}{|l|l|l|l|l|}
\hline Month(s) & $\begin{array}{l}\text { Temperature } \\
{ }^{\circ} \mathbf{C}\end{array}$ & $\mathbf{p}$ & Sunshine hours & $\mathbf{p}$ \\
\hline June & -0.05 & 0.57 & 0.05 & 0.60 \\
\hline July & 0.51 & 0.00 & 0.48 & 0.00 \\
\hline August & 0.48 & 0.00 & 0.37 & 0.00 \\
\hline September & 0.26 & 0.00 & 0.20 & 0.03 \\
\hline June/July & 0.29 & 0.00 & 0.36 & 0.00 \\
\hline July/August & 0.62 & 0.00 & 0.55 & 0.00 \\
\hline June to August & 0.45 & 0.00 & 0.46 & 0.00 \\
\hline
\end{tabular}

579 

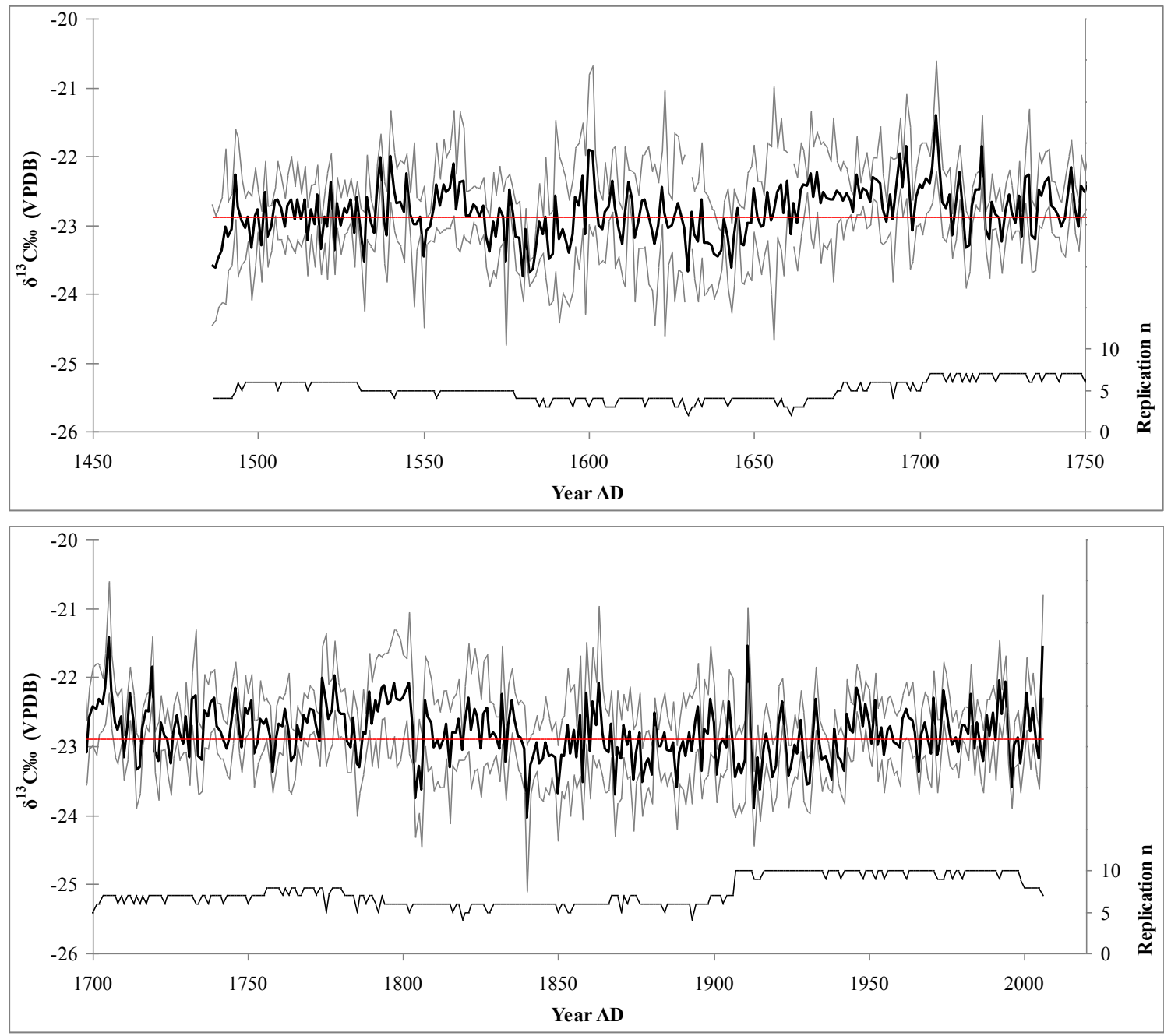

Figure 1. The mean isotope chronology (black) with 95\% confidence limits (grey) and replication. The horizontal (red) line is the mean of the $20^{\text {th }}$ century. 


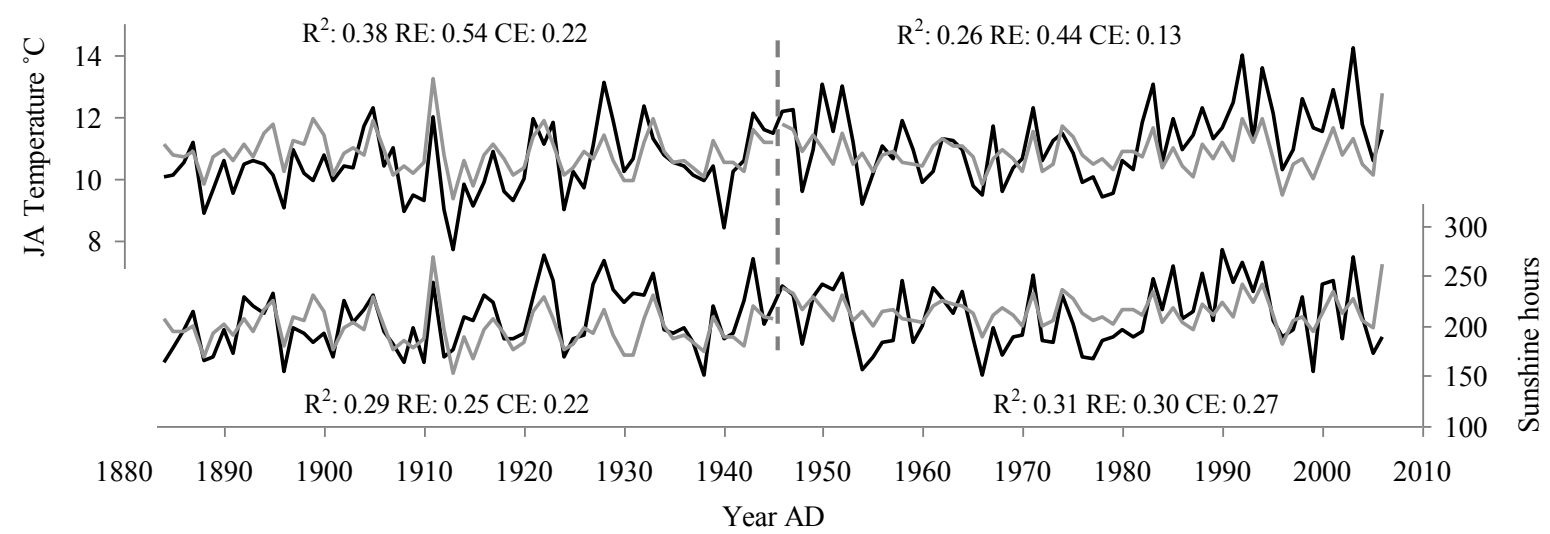

Figure 2. Measured (black) and predicted (grey) values for July/August temperature and 597 sunshine hours using split-period calibration and verification. $\mathrm{R}^{2}$ is the squared correlation 598 between predicted and measured values, RE and CE are Reduction of Error and Coefficient

599 of Efficiency statistics.

600 


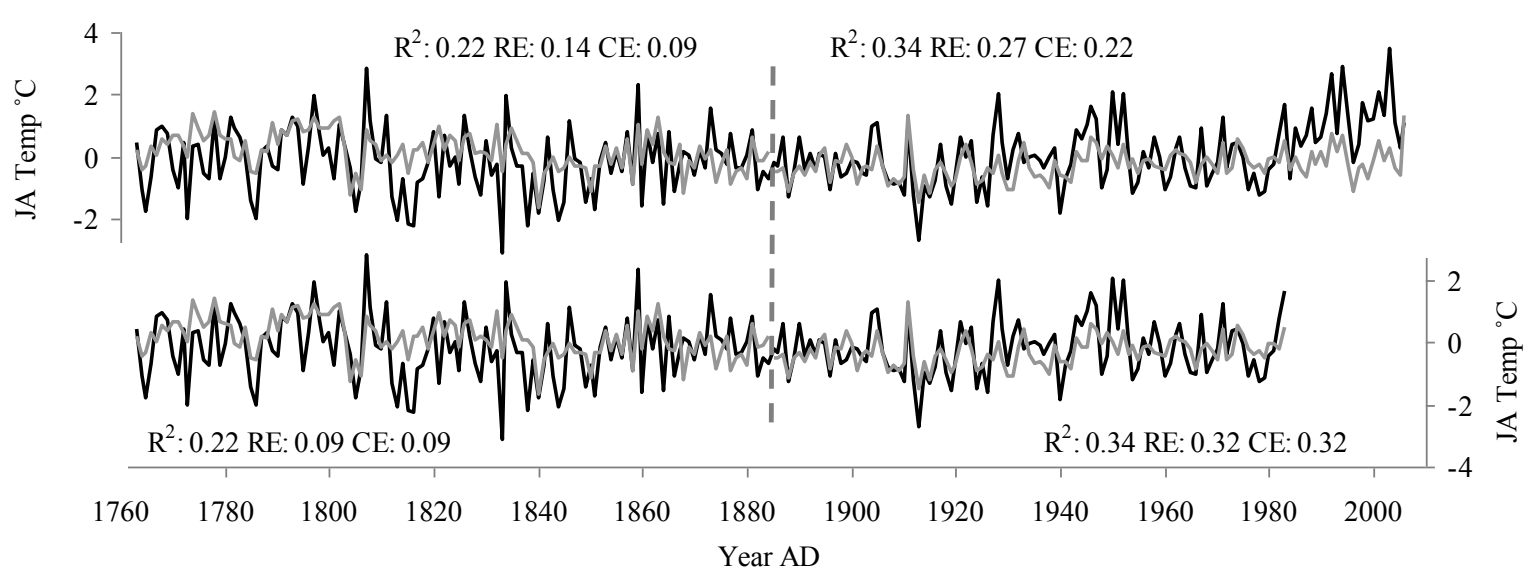

604

605 Figure 3. Measured (black) and predicted (grey) values for July/August temperature 606 anomalies (relative to AD1901 to 2000) using split-period calibration and verification. $\mathrm{R}^{2}$ is 607 the squared correlation between predicted and measured values, RE and CE are Reduction of 608 Error and Coefficient of Efficiency statistics. In the lower graph the modern part of the 609 records has been truncated at AD1983 to check the effect of removing the period of clear 610 offset. 

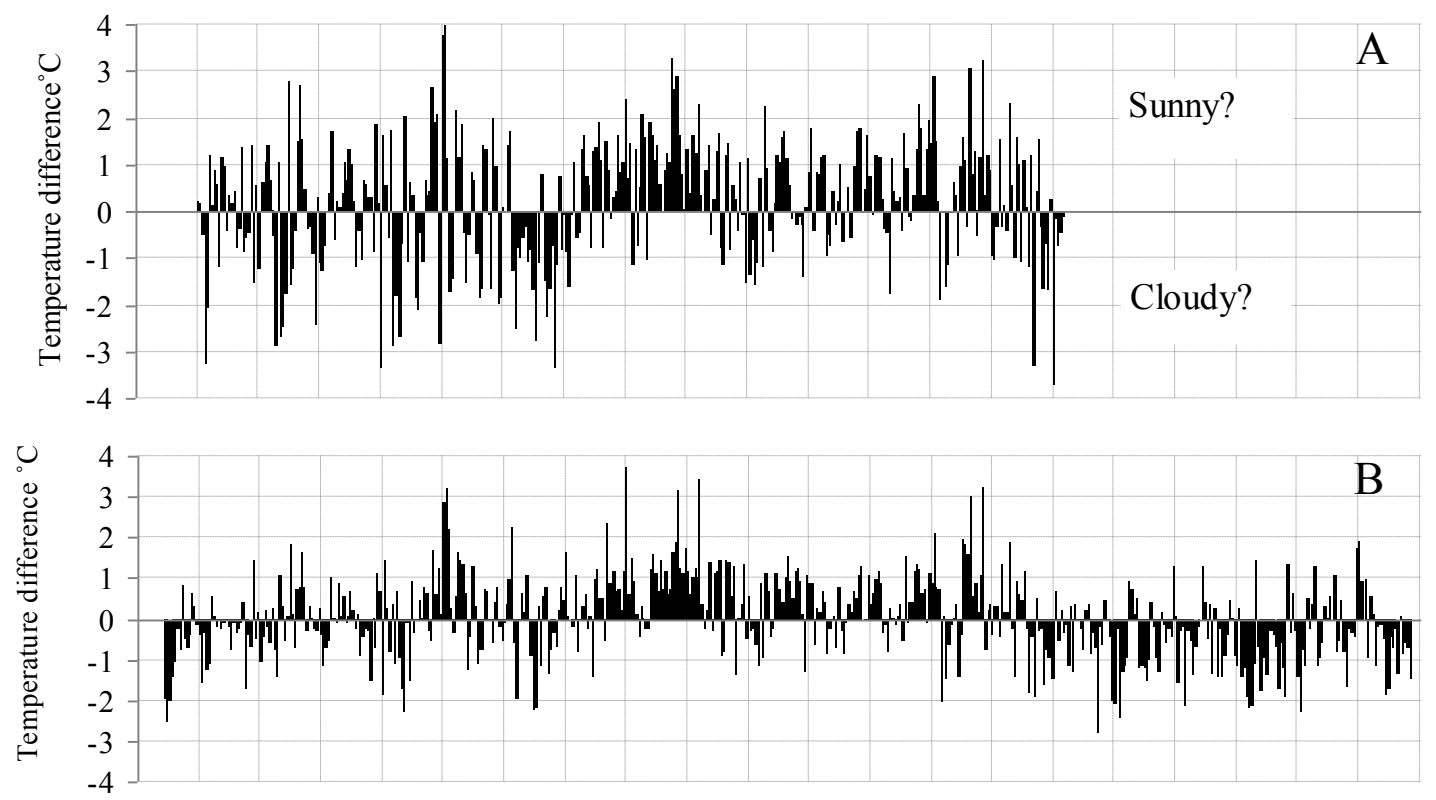

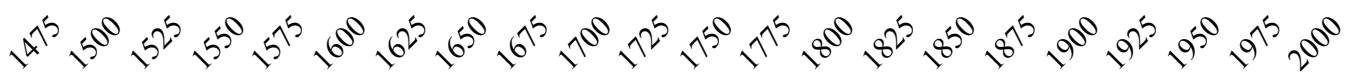

Year AD

613

614

615

616

617

618

619

620

621

622 623

Figure 4. Difference in temperature reconstructed by scaling the $\delta^{13} \mathrm{C}$ chronology to fit the mean and variance of two summer temperature reconstructions for (A) Central Europe (Dobrovolný et al. 2010) and (B) the Greater Alpine Region (Trachsel et al. 2012). The shorter Central European record is based on documentary evidence and represents the mean JA temperature relative to AD1961 to 1990. The longer Greater Alpine Region record is a multi-proxy reconstruction of JJA temperature relative to the period AD1901 to 2000 . Positive values indicate that $\delta^{13} \mathrm{C}$ would over-estimate temperature. An alternative explanation is that the positive and negative values indicate periods of high and low sunshine. 
625

626

627

628

629

630

631

632

633

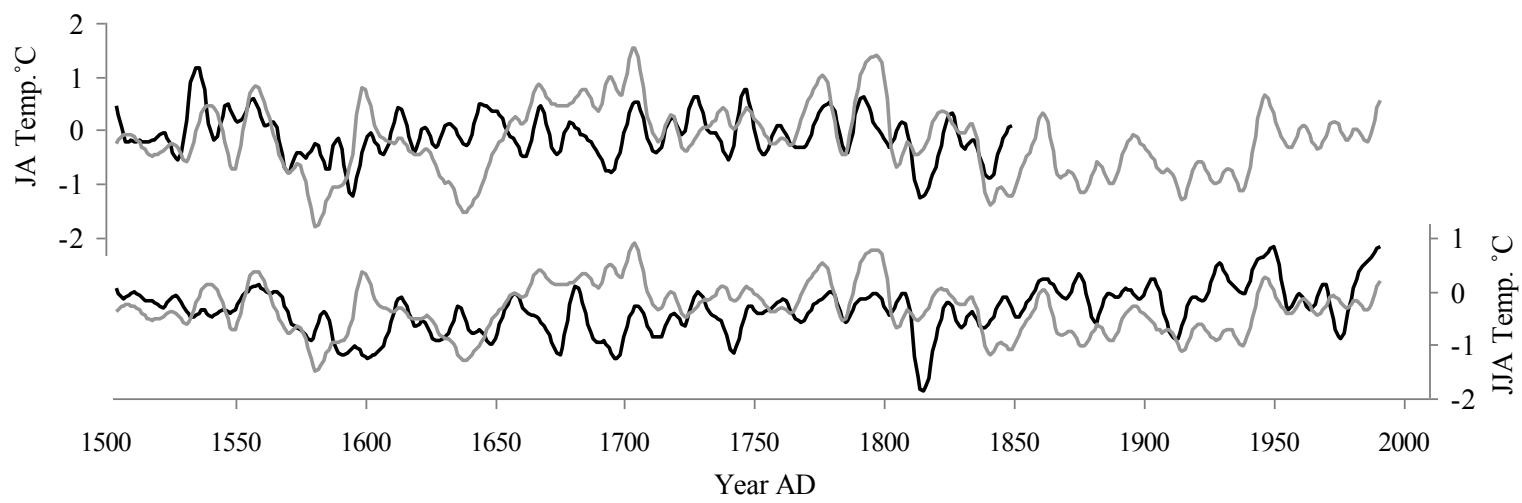

Figure 5. Temperature reconstructions (upper) for Central Europe (July/August: Dobrovolný et al, 2010) and (lower) for the Greater Alpine Region (June to August: Trachsel et al. 2012) compared with the $\delta^{13} \mathrm{C}$ chronology (in grey) scaled to match their mean and variance. Values are temperature anomalies relative to AD1961 to 1990 (upper) and to AD1901 to 2000 (lower) smoothed with a 10yr Gaussian filter. 

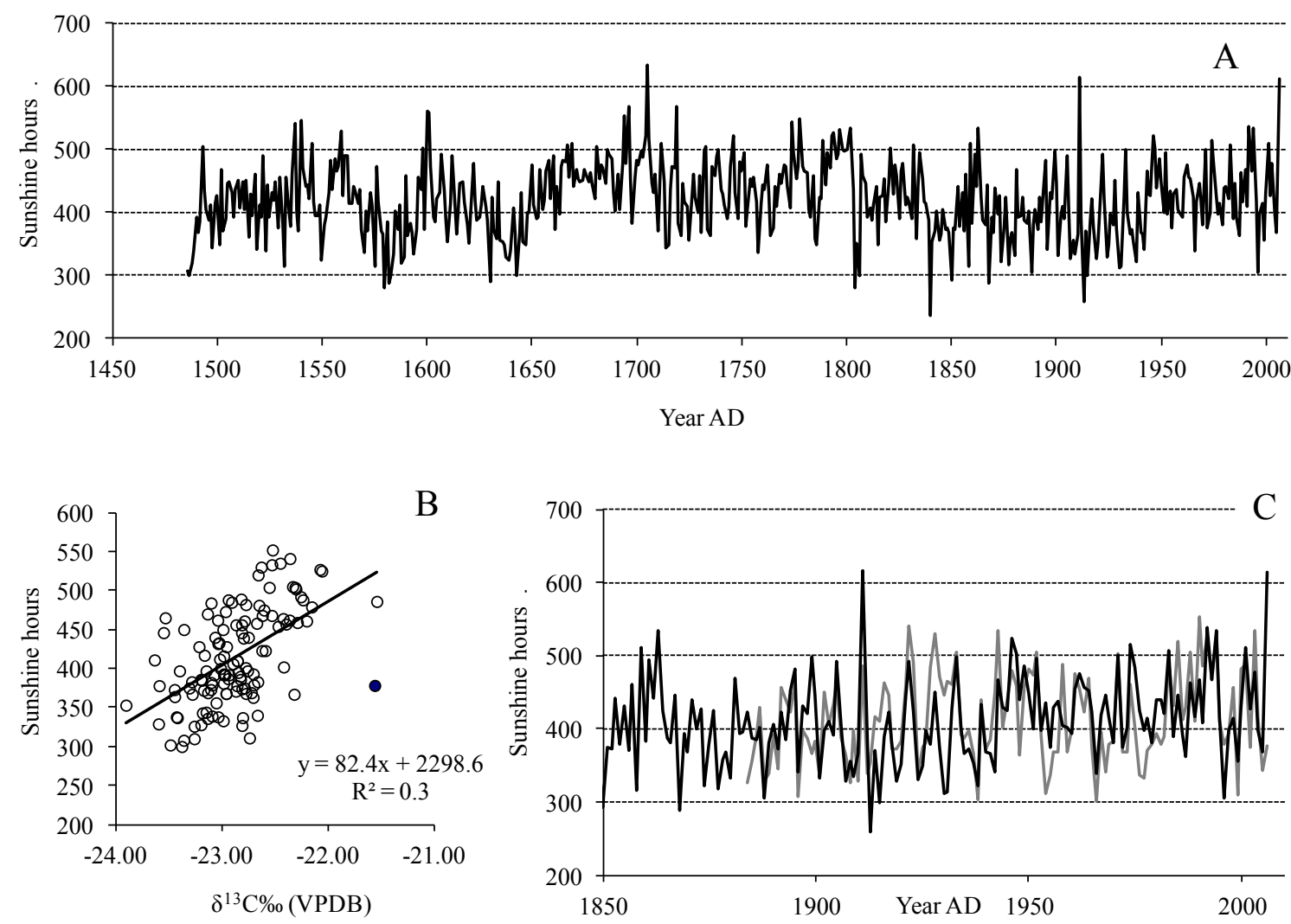

635 Figure 6. July and August total sunshine hours reconstruction based on $\delta^{13} \mathrm{C}$ from high 636 altitude larch trees (A) and a scatter plot (B) and line-graph (C) showing the fit with sunshine 637 hours measured at Villacher Alps in the Austrian Alps (measured series is the shorter grey 638 line). Note that AD2006 is a clear outlier (filled dot on B) possibly reflecting the extreme dry 639 conditions experienced during this year. 